\title{
KINERJA PROGRAM KESEHATAN DAN KESELAMATAN KERJA (K3) DI PERUSAHAAN PLYWOOD TAHUN 2012-2016
}

\author{
OCCUPATIONAL HEALTH AND SAFETY (OHS) PERFORMANCE \\ PROGRAMS ON PLAYWOOD FACTORY IN 2012-2016
}

\author{
Nikita Ayu Dwijayanti \\ PT. Wijaya Karya \\ E-mail: nikitasarajiva20@gmail.com
}

\begin{abstract}
PT. Kutai Timber Indonesia (KTI) was a company that belongs to the timber sector. Occupational accident frequently happened on PT. KTI and those ccupational accidents must be reported and recorded to monitor occupational health and safety (OHS) performance program. The aim of this study was to measure OHS performance on PT. KTI in 2012-2016 with occupational accident statistic. This research was descriptive study that explained occupational accident statistic and OHS programs in PT. KTI. The statistic of occupational accident that include incident rate, frequency rate, severity rate and safe T-score. The data collection was through secondary data, observation sheets, and questionnaires. The results of this research were 303 occupational accidents that happened since 2012 until 2016. The highest incident based on Statistic calculation of occupational accident were incident rate and frequency rate in 2012, meanwhile the highest severity rate occurred in 2012, 2015, and 2016. Based on safe T-score calculation OHS Performance just increased in 2015.The result of this study was being affected by the OHS programs that had not changed since 2012 until 2016.3 out of 11 programs had unfulfilled criterias under 50\%, those were bus employees, planning and implementation of JSA and implementation of OHS.
\end{abstract}

Keywords: OHS performance, OHS program, statistic of occupational accidents

\begin{abstract}
ABSTRAK
PT. Kutai Timber Indonesia (KTI) merupakan perusahaaan di bidang perkayuan. Kecelakaan kerja sering terjadi di PT. KTI. Kecelakaan kerja wajib dilaporkan dan dicatat sebagai bentuk monitoring terhadap performa kinerja K3 di suatu perusahaan. Tujuan penelitian ini adalah untuk menilai kinerja K3 di PT. Kutai Timber Indonesia pada tahun 2012-2016 menggunakan statistik kecelakaan kerja. Penelitian ini bersifat deskriptif yakni menggambarkan statistik kecelakaan kerja dan pelaksanaan program kerja K3 di PT KTI. Statistik kecelakaan kerja meliputi incident rate, frequency rate, severity rate dan safe T-score. Pengumpulan data menggunakan data sekunder, lembar observasi dan wawancara. Hasil penelitian menunjukkan bahwa terjadi 303 kejadian kecelakaan kerja selama tahun 2012-2016. Hasil perhitungan statistik kecelakaan kerja didapatkan nilai incident rate dan frequency rate tertinggi terjadi pada tahun 2012, sedangkan, severity rate tertinggi terjadi pada tahun 2012, 2015 dan 2016. Berdasarkan perhitungan Safe T-Score, kinerja K3 hanya mengalami peningkatan pada tahun 2015. Hasil ini dipengaruhi oleh program kerja yang tidak banyak mengalami perubahan mulai tahun 2012 hingga tahun 2016. Dari 11 program kerja, terdapat 3 program kerja yang pemenuhan kriterianya di bawah $50 \%$, yakni bus karyawan, penyusunan dan pelaksanaan JSA dan pelaksanaan K3.
\end{abstract}

Kata kunci: kinerja K3, program K3, statistik kecelakaan kerja

\section{PENDAHULUAN}

Kecelakaan kerja adalah kejadian yang berhubungan dengan pekerjaan yang dapat menyebabkan cedera, kesakitan dan kematian (AS/NZS 4801:2001). Kejadian kecelakaan kerja dapat disebabkan beberapa faktor penyebab yang saling terkait. Menurut Heinrich (1980) kecelakaan kerja disebabkan oleh unsafe action sebesar $88 \%$, unsafe condition sebesar $10 \%$ dan act of god atau kecelakaan yang tidak dapat dicegah sebesar $2 \%$. 
Angka kecelakaan kerja di Indonesia masih sangat tinggi, hal ini dibuktikan pada tahun 2010 Indonesia menempati peringkat 152 dari 153 negara untuk kejadian kecelakaan kerja terendah. Berdasarkan laporan data Badan Penyelenggara Jaminan Sosial Tenaga Kerja (BPJS TK), angka kecelakaan kerja di Indonesia pada tahun 2011-2015 tergolong fluktuatif. Pada tahun 2011 terdapat 99.491 kasus kecelakaan kerja, tahun 2012 terdapat 103.000 kasus kecelakaan kerja, tahun 2013 terdapat 10.493 kasus kecelakaan kerja, tahun 2014 terdapat 10.002 kasus kecelakaan kerja dan tahun 2015 terdapat 105.182 kasus kecelakaan kerja.

Berdasarkan Peraturan Menteri Nomor 3 Tahun 1998 tentang Tata Cara Pelaporan dan Pemeriksaan Kecelakaan dijelaskan bahwa pengurus atau pengusaha wajib melaporkan setiap kecelakaan yang terjadi di tempat kerja. Setelah menerima laporan kecelakaan, selanjutnya dilakukan pemeriksaan dan pengkajian kecelakaan. Informasi yang diketahui pada saat pemeriksaan dicatat dalam laporan kecelakaan kerja.

Semua informasi baik dalam buku catatan kecelakaan kerja atau bentuk laporan kecelakaan kerja perlu dianalisis sebagai salah satu manajemen data. Salah satu bentuk monitoring dapat tersaji melalui statistika kecelakaan kerja. Statistik kecelakaan kerja yang ditentukan ILO (1989) meliputi incident rate, frequency rate, severity rate dan safe T-score. Statistik kecelakaan kerja juga bertujuan untuk menilai OHS Performance Programs. Menggunakan statistik dapat memberikan masukan ke manajemen mengenai tingkat kecelakaan kerja serta berbagai faktor yang dapat digunakan sebagai dasar untuk mencegah terjadinya kecelakaan kerja. Kewajiban untuk melakukan pengukuran kinerja K3 tertuang di dalam klausul 4.5 OHSAS (Occupational Health and Safety Asessment Series) 18001:2007 tentang pemantauan dan pengukuran kinerja.

Berdasarkan penelitian yang dilakukan oleh Romadiaty (2011), penilaian kinerja K3 di PT. Petrokimia Gresik di lihat menggunakan frequency rate, severity rate dan safe T-score. Nilai frequency rate tertinggi adalah pada tahun 2005 dan 2006, severity rate terhadap data kecelakaan kerja selama periode 2005-2009 adalah 0, dan nilai safe T-score adalah $\leq-2,00$ yang menunjukkan bahwa kinerja K3 PT. Petrokimia Gresik semakin membaik.

Statistik kecelakaan kerja juga digunakan sebagai penilaian safety performance di pembangkit listrik tenaga uap di India selama periode 2007-2014
(Kumar, 2015). Hasil penelitiannya menunjukkan bahwa incident rate selama tahun 2007-2014 semuanya tergolong tinggi, dengan nilai paling tinggi terjadi pada tahun 2011 yakni sebesar 54,2. Hasil frequency rate menunjukkan bahwa pada tahun 2011 terjadi 22,3 kecelakaan kerja per satu juta jam kerja. Hasil severity rate pada tahun 2011 menunjukkan bahwa terdapat 23,1 hari kerja yang hilang akibat kecelakaan kerja per satu juta jam kerja. Hasil safe T-score menunjukkan bahwa kinerja $\mathrm{K} 3$ di pembangkit listrik tenaga uap di India mengalami peningkatan pada tahun 2008 dan 2010.

Berdasarkan penelitian di atas, statistik kecelakaan kerja pada umumnya digunakan sebagai penilaian kinerja $\mathrm{K} 3$ di suatu perusahaan atau instansi. Penilaian kinerja dengan statistik kecelakaan kerja merupakan cara untuk mengevaluasi kinerja $\mathrm{K} 3$ dengan melihat data kecelakaan kerja sebagai sumber utama. Selain itu, analisis statistik kecelakaan kerja bertujuan untuk mengetahui kejadian kecelakaan kerja yang sebenarnya, tingkat keparahan dan gambaran pelaksanaan program K3 sebelumnya sehingga dapat dijadikan rekomendasi untuk membuat suatu program pencegahan kecelakaan kerja.

Selama tahun 2012-2014, tercatat telah terjadi 303 kecelakaan kerja di PT. KTI. PT. KTI telah mendapatkan OHSAS 18001 mulai tahun 2013. Berdasarkan hasil wawancara dengan Representatif Divisi KL (Keselamatan dan Lingkungan) PT. KTI menjelaskan bahwa PT. KTI belum pernah melakukan statistik kecelakaan kerja untuk menilai kinerja K3. Oleh karena itu penelitian ini bertujuan untuk menilai kinerja K3 di PT. Kutai Timber Indonesia selama tahun 2012-2016 menggunakan statistik kecelakaan kerja.

\section{METODE}

Penelitian ini merupakan penelitian deskriptif dimana peneliti menggambarkan secara objektif, sistematis, faktual, dan akurat mengenai fakta yang diteliti. Berdasarkan metode yang digunakan penelitian ini termasuk penelitian observasional karena dalam pengambilan data, peneliti tidak memberikan perlakuan apapun terhadap objek penelitian. Menurut waktu pelaksanaannya penelitian ini adalah penelitian cross sectional karena dilakukan dalam satu periode.

Penelitian dilakukan di PT. Kutai Timber Indonesia yang berlokasi di Kota Probolinggo. Waktu pengumpulan data dilakukan pada Juni 
2017. Cara pengumpulan data menggunakan data primer dan data sekunder. Data primer didapatkan dengan observasi dan wawancara, sedangkan data sekunder didapatkan dari studi dokumen dan profil perusahaan PT. Kutai Timber Indonesia. Subjek dalam penelitian ini adalah seluruh pekerja PT. Kutai Timber Indonesia yang pernah mengalami kecelakaan kerja selama tahun 2012-2016.

Data hasil penelitian yang telah diperoleh di lapangan akan dikumpulkan dan diolah untuk mengetahui perubahan kinerja K3 menggunakan perhitungan statistik kecelakaan kerja yang terdiri dari incident rate, frequency rate, severity rate dan safe T-score. Statistik kecelakaan kerja dapat diketahui dengan menggunakan rumus sebagai berikut:

\section{Incident rate}

Incident rate adalah angka yang menunjukkan kecelakaan kerja dari seribu tenaga kerja. Incident rate dihitung dengan rumus:

$\mathrm{IR}=\frac{\sum \text { kecelakaan kerja tahun } x}{\sum \text { jumlah pekerja tahun } x} \times 1000$

Pengelompokan hasil perhitungan incident rate tergolong tinggi bila perusahaan dengan jumlah pekerja 1-10 dengan IR $>2,1$, perusahaan dengan jumlah pekerja 11-49 dengan IR $>1,2$, perusahaan dengan jumlah pekerja 50-249 dengan IR $>2,7$, dan perusahaan dengan jumlah pekerja 250-999 dengan IR > 1,1 (Silalahi, 1995).

\section{Frequency rate}

Frequency rate adalah yang menunjukkan jumlah kejadian kecelakaan kerja per satu juta jam kerja orang. Frequency Rate dihitung dengan rumus:

$\mathrm{FR}=\frac{\sum \text { kecelakaan kerja tahun } x}{\sum \text { jumlah pekerja tahun } x} \times 1.000 .000$

Frequency rate menunjukkan tingkat bahaya tempat kerja. Tingkat bahaya perusahaan tergolong tinggi jika FR $\geq 10$, tergolong sedang jika $5<\mathrm{FR}$ $<10$, dan tergolong rendah jika FR $\leq 5$ (Silalahi, 1995).

\section{Severity Rate}

Severity rate adalah angka yang menunjukkan total hari kerja yang hilang akibat kecelakaan kerja per satu juta jam kerja orang. Severity rate dihitung dengan rumus:

$\mathrm{SR}=\frac{\sum \text { hari kerja hilang tahun } x}{\sum \text { jumlah pekerja tahun } x} \times 1.000 .000$

Tingkat keparahan merupakan ukuran dengan cutting point 0 , perusahaan seharusnya tidak kehilangan hari kerja produktif akibat kecelakaan kerja (Silalahi, 1995).

\section{Safe T-score}

Safe T-Score digunakan untuk membandingkan tingkat kecelakaan tahun sekarang dengan tahun sebelumnya. Safe T-Score dihitung dengan rumus:

$$
\text { Safe T-Score }=\frac{\text { FRtahun } x-\text { FRtahun }(x-1)}{\sqrt{\frac{\text { FRtahun }(x-1)}{1.000 .000}}}
$$

Jika hasil perhitungan safe T-score menunjukkan hasil $+2,00--2,00$ berarti program pengendalian kecelakaan kerja tidak menunjukkan perubahan berarti antara tahun $\mathrm{x}$ dengan tahun $(\mathrm{x}-1)$. Jika hasil safe $T$-score $\geq+2,00$ berarti program pengendalian kecelakaan kerja mengalami penurunan di tahun $\mathrm{x}$ dibandingkan dengan tahun (x-1). Jika hasil safe T-score $\leq-2,00$ berarti program $\mathrm{K} 3$ mengalami perbaikan di tahun $\mathrm{x}$ dibandingkan dengan tahun (x-1) (Silalahi, 1995).

\section{HASIL}

\section{Kecelakaan Kerja}

Berdasarkan tabel 1 diketahui bahwa selama tahun 2012 hingga 2016 telah terjadi 303 kejadian kecelakaan kerja di PT. Kutai Timber Indonesia. Angka kejadian kecelakaan tertinggi terjadi pada tahun 2012 sebanyak 84 kejadian kecelakaan, sedangkan angka kecelakaan terendah terjadi pada tahun 2015 sebanyak 42 kejadian.

\section{Statistik Kecelakaan Kerja}

Statistik kecelakaan kerja merupakan salah satu bentuk upaya peningkatan keselamatan kerja perusahaan dalam bentuk penilaian kinerja K3. Adanya statistik kecelakaan dari tahun ke tahun dapat bermanfaat untuk melihat tren kejadian kecelakaan perhitungan statistik kecelakaan 
Tabel 1. Distribusi Kecelakaan Kerja di PT. Kutai Timber Indonesia Tahun 2012-2016

\begin{tabular}{ccc}
\hline \multirow{2}{*}{ Tahun } & \multicolumn{2}{c}{ Kejadian Kecelakaan Kerja } \\
\cline { 2 - 3 } & Frekuensi & Persentase (\%) \\
\hline 2012 & 84 & 27,6 \\
2013 & 68 & 22,4 \\
2014 & 59 & 19,4 \\
2015 & 42 & 14,1 \\
2016 & 50 & 16,5 \\
Total & $\mathbf{3 0 3}$ & $\mathbf{1 0 0}$ \\
\hline
\end{tabular}

kerja meliputi Incident Rate, Frequency Rate, Severity Rate, dan Safe T-Score. Untuk melakukan perhitungan statistika kecelakaan kerja, diperlukan data mengenai jumlah pekerja per tahun, jumlah jam kerja pertahun, serta jumlah hari hilang per tahun akibat kecelakaan kerja.

\section{Incident Rate}

Perhitungan incident rate menggunakan rumus sebagai berikut:

$$
\mathrm{IR}=\frac{\sum \text { kecelakaan kerja tahun } x}{\sum \text { jumlah pekerja tahun } x} \times 1000
$$

Berdasarkan tabel 3 diketahui bahwa incident rate kecelakaan kerja PT. Kutai Timber Indonesia pada tahun 2012 hingga 2016 tergolong tinggi, karena melebihi standar yakni IR $>1,1$. Incident rate pada periode 2012-2016 cenderung menurun, kecuali pada tahun 2016 mengalami peningkatan sebesar 1,9. Tahun 2012 menghasilkan incident rate tertinggi, yakni sebesar 22,1 yang berarti dari 1.000 pekerja terjadi 22 kecelakaan kerja. Tahun 2013 menghasilkan incident rate sebesar 17,6 yang berarti dari 1.000 pekerja terjadi 18 kecelakaan kerja. Tahun 2014 menghasilkan incident rate sebesar 15 yang
Tabel 3. Hasil Perhitungan Icident Rate Kecelakaan Kerja PT. KTI Tahun 2012-2016

\begin{tabular}{cc}
\hline Tahun & Incident Rate \\
\hline 2012 & 22,1 \\
2013 & 17,6 \\
2014 & 15 \\
2015 & 10,6 \\
2016 & 12,5 \\
\hline
\end{tabular}

berarti dari 1.000 pekerja terjadi 15 kecelakaan kerja. Selanjutnya tahun 2015 menghasilkan incident rate sebesar 10,6 yang berarti dari 1.000 pekerja terjadi 11 kecelakaan kerja. Terakhir pada tahun 2016 menghasilkan incident rate sebesar 12,5 yang berarti dari 1.000 pekerja terjadi 12 kecelakaan kerja.

\section{Frequency Rate}

Perhitungan frequency rate menggunakan rumus sebagai berikut:

$$
\mathrm{FR}=\frac{\sum \text { kecelakaan kerja tahun } x}{\sum \text { jumlah pekerja tahun } x} \times 1.000 .000
$$

Tabel 4 menunjukkan bahwa pada tahun 2012, PT. Kutai Timber Indonesia tergolong perusahaan dengan tingkat bahaya tinggi, dikarenakan FR $\geq 10$. Nilai kekerapan kejadian Kecelakaan kerja pada tahun 2012 sebesar 10,6 yang bermakna terjadi 11 kecelakaan kerja pada setiap 1.000.000 jam kerja pada total 3801 orang pekerja. Pada tahun 2012 hingga 2016 terjadi penurunan frequency rate dengan $5<$ FR $<10$, sehingga PT. Kutai Timber Indonesia tergolong perusahaan dengan tingkat bahaya sedang. Tahun 2013 memiliki frequency rate

Tabel 2. Hasil Perhitungan Jumlah Pekerja, Jumlah Jam Kerja dan Jumlah Hari Hilang Akibat Kecelakaan Kerja di PT. Kutai Timber Indoensia Tahun 2012-2016

\begin{tabular}{ccccc}
\hline Tahun & $\begin{array}{c}\text { Jumlah Kecelakaan } \\
\text { Kerja }\end{array}$ & $\begin{array}{c}\text { Jumlah Pekerja } \\
\text { (orang) }\end{array}$ & Jumlah Jam Kerja & Jumlah Hari Hilang \\
\hline 2012 & 84 & 3801 & 7.899 .912 & 6871 \\
2013 & 68 & 3859 & 8.052 .352 & 2730 \\
2014 & 59 & 3938 & 8.221 .311 & 268 \\
2015 & 42 & 3964 & 8.273 .993 & 6455 \\
2016 & 50 & 4001 & 8.350 .632 & 6432 \\
\hline
\end{tabular}


Tabel 4. Hasil Perhitungan Frequency Rate Kecelakaan Kerja PT. KTI Tahun 20122016

\begin{tabular}{cc}
\hline Tahun & Frequency Rate \\
\hline 2012 & 10,6 \\
2013 & 8,44 \\
2014 & 7,18 \\
2015 & 5,08 \\
2016 & 5,98 \\
\hline
\end{tabular}

sebesar 8,44 yang bermakna terjadi 9 kecelakaan kerja pada setiap 1.000.000 jam kerja pada total 3859 orang pekerja. Tahun 2014 memiliki nilai kekerapan sebesar 7,18yang bermakna terjadi 8 kecelakaan kerja pada setiap 1.000 .000 jam kerja pada total 3938 orang pekerja. Selanjutnya tahun 2015 memiliki frequency rate sebesar 5,08yang bermakna terjadi 6 kecelakaan kerja pada setiap 1.000.000 jam kerja pada total 3964 orang pekerja. Pada tahun 2016 nilai kekerapan mengalami peningkatan menjadi 5,98 yang bermakna terjadi 6 kecelakaan kerja pada setiap 1.000 .000 jam kerja pada total 4001 orang pekerja.

\section{Severity Rate}

Perhitungan severity rate menggunakan rumus sebagai berikut:

$$
\mathrm{SR}=\frac{\sum \text { hari kerja hilang tahun } x}{\sum \text { jumlah pekerja tahun } x} \times 1.000 .000
$$

Tabel 5 menunjukkan nilai keparahan Kecelakaan kerja yang terjadi di PT. Kutai Timber Indonesia pada tahun 2012 hingga 2016 melebihi cutting point 0 , yakni perusahaan seharusnya tidak kehilangan hari kerja produktif akibat kecelakaan kerja. Tahun 2012 menghasilkan severity rate sebesar 869,75 yang bermakna terjadi 870 hari kerja yang hilang akibat kecelakaan kerja setiap 1.000 .000 jam kerja pada total 3801 orang pekerja. Pada tahun 2013 severity rate mengalami penurunan, yakni sebesar 339 yang bermakna terjadi 339 hari kerja yang hilang akibat kecelakaan kerja setiap 1.000.000 jam kerja pada total 3859 orang pekerja. Tahun 2014 nilai keparahan mengalami penurunan yang cukup signifikan, yakni 32,6 yang bermakna terjadi 33 hari kerja yang hilang akibat kecelakaan kerja setiap 1.000 .000 jam kerja pada total 3938 orang pekerja. Tahun 2015 severity rate mengalami peningkatan
Tabel 5. Hasil Perhitungan Severity Rate Kecelakaan Kerja PT. KTI Tahun 2012-2016

\begin{tabular}{cc}
\hline Tahun & Severity Rate \\
\hline 2012 & 869,75 \\
2013 & 339 \\
2014 & 32,6 \\
2015 & 780,15 \\
2016 & 770,2 \\
\hline
\end{tabular}

yang sangat tinggi, yakni sebesar 780,15 yang bermakna terjadi 781 hari kerja yang hilang akibat kecelakaan kerja setiap 1.000.000 jam kerja pada total 3964 orang pekerja. Tahun 2016 nilai kekerapan sebesar 770,2 yang bermakna terjadi 771 hari kerja yang hilang akibat kecelakaan kerja setiap 1.000.000 jam kerja pada total 4001 orang pekerja.

\section{Safe T-Score}

Perhitungan safe T-score menggunakan rumus sebagai berikut:

$$
\text { Safe T-Score }=\frac{\text { FRtahun } x-\text { FRtahun }(x-1)}{\sqrt{\frac{\text { FRtahun }(x-1)}{\text { jamkerjatahun } x}}}
$$

Berdasarkan tabel 6 diketahui bahwa pada tahun 2013 dan 2014 tidak terjadi perubahan bermakna baik peningkatan maupun penurunan dalam pelaksanaan upaya pencegahan kecelakaan kerja, hal ini dibuktikan oleh nilai Safe T-Score pada tahun 2013 dan 2014 berada dalam interval -2 hingga +2. Pada tahun 2015 nilai perhitungan Safe T-Score menunjukkan angka $-2,25$ yang bermakna program K3 pada tahun 2015 mengalami perbaikan dibandingkan tahun sebelumnya. Pada tahun 2016 nilai Safe T-Score menjadi 1,15 yang bermakna program pengendalian kecelakaan kerja tidak

Tabel 6. Hasil Perhitungan Safe T-Score Kecelakaan

\begin{tabular}{|c|c|}
\hline Tahun & Safe T-Score \\
\hline 2013 & $-1,88$ \\
\hline 2014 & $-1,24$ \\
\hline 2015 & $-2,25$ \\
\hline 2016 & 1,15 \\
\hline
\end{tabular}
Kerja PT. KTI Tahun 2012-2016 
mengalami perubahan berarti dibandingkan tahun sebelumnya.

\section{Program K3 PT. Kutai Timber Indonesia}

Berdasarkan hasil wawancara kepada representatif Divisi Keselamatan dan Lingkungan PT. Kutai Timber Indonesia dan observasi lapangan, diketahui terdapat 7 program kerja utama sebagai upaya pengendalian kecelakaan kerja yakni Safety Patroll Ass Man Up, Meeting Safety Management, Piket Staff, Reward Zero Accident, Safety Riding, Bus Karyawan dan Visual Management. Selain itu terdapat 4 program yang ditemukan saat observasi lapangan, yakni pengecekan APAR, hydrant, dan listrik.

Berdasarkan hasil wawancara dengan representatif Divisi Keselamatan dan Lingkungan, diketahui terdapat 51 kriteria observasi upaya pengendalian kecelakaan kerja di PT. Kutai Timber Indonesia. Berdasarkan hasil observasi, pemenuhan pelaksanaan program berdasarkan hasil pengamatan

Tabel 7. Pemenuhan Kriteria Pelaksanaan Upaya Pencegahan Kecelakaan Kerja di PT. KTI Tahun 2012-2016

\begin{tabular}{|c|c|c|c|c|}
\hline No & $\begin{array}{c}\text { Upaya } \\
\text { Pengendalian }\end{array}$ & $\begin{array}{c}\text { Total } \\
\text { Kriteria }\end{array}$ & $\begin{array}{c}\text { Kriteria } \\
\text { Terpenuhi }\end{array}$ & $(\%)$ \\
\hline 1 & $\begin{array}{l}\text { Safety Patroll } \\
\text { Ass Man Up }\end{array}$ & 7 & 5 & 71 \\
\hline 2 & $\begin{array}{l}\text { Meeting Safety } \\
\text { Management }\end{array}$ & 5 & 5 & 100 \\
\hline 3 & Piket Staff & 4 & 3 & 75 \\
\hline 4 & $\begin{array}{l}\text { Reward Zero } \\
\text { Accident }\end{array}$ & 6 & 5 & 83 \\
\hline 5 & $\begin{array}{l}\text { Pengecekan } \\
\text { APAR, Hydrant } \\
\text { dan Listrik }\end{array}$ & 4 & 3 & 75 \\
\hline 6 & Safety Riding & 5 & 3 & 60 \\
\hline 7 & Bis Karyawan & 3 & 1 & 33 \\
\hline 8 & $\begin{array}{l}\text { Visual } \\
\text { Management }\end{array}$ & 3 & 3 & 100 \\
\hline 9 & $\begin{array}{l}\text { Penyusunan dan } \\
\text { Pelaksanaan } \\
\text { JSA / IBREB }\end{array}$ & 7 & 3 & 43 \\
\hline 10 & $\begin{array}{l}\text { Promosi } \\
\text { Kesehatan dan } \\
\text { Keselamatan }\end{array}$ & 6 & 3 & 50 \\
\hline 11 & Pelaksanaan K3 & 2 & 0 & 0 \\
\hline \multicolumn{2}{|c|}{ Total } & 51 & 34 & 67 \\
\hline
\end{tabular}

masih memenuhi $67 \%$ dari total 51 kriteria. Program yang memiliki penilaian terbaik adalah meeting safety management dan visual management, masingmasing mendapatkan penilaian sempurna yakni $100 \%$. Terdapat 3 program kerja yang pemenuhan kriterianya di bawah $50 \%$, yakni bis karyawan, penyusunan dan pelaksanaan JSA, dan pelaksanaan K3.

\section{PEMBAHASAN}

\section{Kecelakaan Kerja}

Kecelakaan kerja yang terjadi di PT. KTI Berdasarkan catatan kecelakaan kerja selama tahun 2012 hingga 2016 sebanyak 303 kasus. Berdasarkan tabel 1 diketahui bahwa kejadian kecelakaan tertinggi terjadi pada tahun 2012 dan terus menurun hingga tahun 2015. Pada tahun 2016 terjadi peningkatan jumlah kejadian kecelakaan kerja. Berdasarkan hasil wawancara dengan Representatif Divisi KL PT. KTI, peningkatan jumlah kecelakaan kerja disebabkan membaiknya sistem pelaporan kecelakaan kerja yang diiringi dengan terbentuknya Divisi Keselamatan dan Lingkungan

\section{Statistik Kecelakaan Kerja}

\section{Incident Rate}

Incident rate merupakan salah satu perhitungan statistika kecelakaan kerja yang menggambarkan kecelakaan kerja perseribu pekerja. Perhitungan incident rate akurat karena membandingkan antara waktu dengan jumlah pekerja suatu perusahaan. Ada juga yang berpendapat bahwa perhitungan ini belum memuaskan dalam hal kelengkapan karena perhitungan incident rate belum mencakup pekerja part-time, pekerja non-permanen, serta pekerja lembur (Tyler, 2007).

PT. Kutai Timber Indonesia merupakan perusahaan dengan pekerja lebih dari 1.000 tenaga kerja, sehingga tergolong incident rate tinggi jika IR $>1,1$. Pada tabel 3 diketahui bahwa incident rate selama tahun 2012 hingga 2016 tergolong tinggi. incident rate paling tinggi dialami pada tahun 2012 dengan nilai 22,1 yang menunjukkan bahwa pada tahun 2012 terjadi 22 kecelakaan kerja perseribu pekerja. Incident rate yang tinggi menunjukkan bahwa kejadian kecelakaan kerja di PT. KTI sering terjadi. 


\section{Frequency Rate}

Frequency rate atau nilai kekerapan menunjukkan tingkatan bahaya yang dimiliki oleh perusahaan. Perhitungan ini dapat lebih bermanfaat pada setiap organisasi karena mengukur jumlah injury yang terjadi akibat pajanan di tempat kerja dibandingkan dengan total jam kerja. Nilai frequency rate sangat fleksibel dan dapat digunakan untuk mengatur berbagai tipe kecelakaan pada populasi besar (Tyler, 2007).

Berdasarkan hasil perhitungan severity rate di PT. Kutai Timber Indonesia selama tahun 2012 hingga 2016, diketahui bahwa PT. Kutai Timber Indonesia tergolong perusahaan dengan tingkat bahaya sedang. Hal ini dibuktikan dengan nilai Frequency rate selama tahun 2013-2016 adalah $5<\mathrm{FR}<10$. Frequency rate tertinggi terjadi pada tahun 2012 dengan nilai 10,6. Hal ini menunjukkan bahwa pada tahun 2012 terjadi 11 kecelakaan kerja setiap 1.000.000 jam kerja pada 3801 pekerja.

Perhitungan frequency rate dipengaruhi oleh jumlah kejadian kecelakaan kerja dan jumlah jam kerja. Jumlah jam kerja dipengaruhi oleh jumlah pekerja dan jumlah absensi. Semakin tinggi jumlah pekerja maka semakin tinggi pula jumlah jam kerja, sedangkan semakin tinggi jumlah absensi maka semakin rendah jumlah jam kerja. Jumlah pekerja pada tahun 2012 merupakan jumlah pekerja paling rendah selama tahun 2012-2016, namun kejadian kecelakaan pada tahun 2012 paling tinggi dengan 84 kejadian kecelakaan. Tingginya angka kejadian kecelakaan dan rendahnya jumlah tenaga kerja membuat PT. Kutai Timber Indonesia pada tahun 2012 tergolong perusahaan dengan tingkat bahaya tinggi.

\section{Severity Rate}

Severity rate merupakan penilaian statistika kecelakaan kerja yang menunjukkan tingkat keparahan akibat kecelakaan kerja yang terjadi pada pekerja. Tingkat keparahan tersebut dapat dilihat dari jumlah hari kerja hilang. Perhitungan severity rate melihat jumlah hari kerja hilang dibandingkan dengan 1.000 .000 jam kerja produktif. Perhitungan ini tidak dapat mengungkapkan tingkat keparahan injury yang bersifat kronis, seperti hearing loss dan low back pain. Hal ini disebabkan keduanya tidak akan menyebabkan ketidakhadiran pekerja yang signifikan karena gejalanya baru timbul dalam waktu lama (Tyler, 2007).
Berdasarkan pencatatan kecelakaan kerja PT. Kutai Timber Indonesia 2012-2016, didapatkan hasil bahwa severity rate pada tahun 2012, 2015 dan 2016 sangat tinggi. Dalam 1.000 .000 jam kerja produktif, tahun 2012 kehilangan 870 hari, tahun 2015 kehilangan 780 hari dan tahun 2016 kehilangan 770 hari. Tingginya hasil severity rate pada tahun 2012. 2015 dan 2016 disebabkan pada tahun tersebut terjadi kecelakaan kerja yang berakibat meninggal. Berdasarkan Peraturan Menteri Tenaga Kerja No. 03 Tahun 1998 tentang Tata Cara Pelaporan dan Pemeriksaan Kecelakaan, hari kerja hilang pada pekerja yang meninggal terhitung 6000 hari kerja hilang.

\section{Safe T-Score}

Safe T-Score merupakan salah satu perhitungan statistika kecelakaan kerja yang digunakan untuk membandingkan tingkat kecelakaan tahun sekarang dengan tahun sebelumnya. Safe T-Score juga dapat digunakan sebagai pengukuran kinerja K3 yang telah dilakukan oleh sebuah perusahaan setiap tahunnya. Perhitungan Safe T-Score dipengaruhi Frequency rate tahun $\mathrm{x}$ dan Frequency rate tahun $\mathrm{x}-1$.

Hasil perhitungan Safe T-Score di PT. Kutai Timber Indonesia pada tahun 2013, 2014 dan 2016 berada pada rentang +2 hingga -2 , yang menunjukkan bahwa program pengendalian kecelakaan kerja pada tahun tersebut tidak menunjukkan perubahan berarti. Hanya pada tahun 2015 saja program pengendalian kecelakaan kerja mengalami perbaikan dibandingkan dengan tahun 2014, dengan nilai Safe T-Score -2,25. Diketahui berdasarkan tabel 1, kecelakaan kerja pada tahun 2012-2015 mengalami penurunan dan meningkat kembali pada tahun 2016. Hasil wawancara dengan Representatif Divisi KL PT. Kutai Timber Indonesia diketahui bahwa selama tahun 2012-2016 tidak terdapat inovasi maupun perubahan program kerja. Pada tahun 2015 persiapan pembentukan Divisi KL dimulai. Program pengendalian kecelakaan kerja mulai dikaji ulang dan mengalami perbaikan. Pada tahun 2016 Divisi KL mulai resmi beroperasi, program pengendalian yang telah dikaji ulang diterapkan kembali pada tahun 2016. Perubahan program yang terjadi pada tahun 2016 adalah pada sistem pelaporan kecelakaan kerja yang diperketat. 


\section{Program K3 PT. Kutai Timber Indonesia}

\section{Safety Patroll Ass Man Up}

Safety Patroll Ass Man Up adalah program kerja bulanan yang dilakukan rutin pada pertengahan bulan antara tanggal 16 hingga 20. Safety Patroll Ass Man Up merupakan program inspeksi yang diikuti oleh pekerja PT. KTI dengan jabatan fungsi manajerial. Pada penerapannya, Safety Patroll Ass Man Up dibagi menjadi beberapa kelompok, setiap kelompok terdiri dari 4-5 orang. Inspeksi yang dilakukan bertujuan untuk mencegah terjadinya kecelakaan kerja dengan mencari adanya unsafe act dan unsafe condition pada seluruh Unit PT. KTI. Jika dalam pelaksanaannya ditemukan temuan, maka temuan tersebut dilaporkan kepada PIC (Person in Charge) pada unit masing-masing. Temuan tersebut sudah harus mendapatkan tindak lanjut, maksimal 1 bulan setelah dilaporkan.

Berdasarkan tabel 7 diketahui bahwa program safety patroll ass man up memenuhi 5 dari 7 kriteria. Hal ini disebabkan kerahasiaan pelaksanaan program ini masih belum terjaga sepenuhnya. Masih terdapat beberapa pekerja yang mengetahui waktu program ini akan dilaksanakan, sehingga unit pekerja tersebut lebih rapi dari biasanya. Selain itu, tindak lanjut terhadap temuan yang didapatkan seharusnya telah dilaporkan kepada Divisi KL maksimal 5 bulan. Masih terdapat beberapa unit yang tidak melaporkannya sampai satu bulan, sehingga representatif KL meminta laporan tersebut sekaligus menegur.

\section{Piket Staff}

Piket staff merupakan program pengawasan yang dilakukan oleh seorang askabag atau kabag di PT. KTI pada setiap Minggu. Pelaksanaan piket staff dilakukan secara terjadwal bagi masing-masing askabag atau kabag. Pengawasan dilakukan dengan menginspeksi keamanan dan kondisi tempat kerja. Pemilihan Minggu dikarenakan pada Minggu kondisi pabrik sepi disebabkan pekerja yang datang hanya sedikit, sehingga keamanan kondisi pabrik pun menurun.

Pelaksanaan piket staff memenuhi 3 dari 4 kriteria. Piket staff telah dilakukan setiap hari minggu oleh Ass. Kabag atau kabag, namun masih terdapat temuan yang tidak dilaporkan oleh pengawas. Hal ini dikarenakan pengawas merasa temuan tersebut tidak terlalu besar, sehingga tidak perlu dilaporkan.

\section{Reward Zero Accident}

Reward Zero Accident merupakan program pemberian hadiah kepada unit kerja yang dapat mempertahankan status zero accident pada jumlah hari tertentu. Penentuan jumlah hari pada masingmasing unit berbeda, hal ini dipengaruhi oleh jumlah pekerja dan tingkatan bahaya pada unit tersebut. Suatu unit dikatakan zero accident jika dalam unit tersebut tidak terdapat kejadian kebakaran, kecelakaan lalu lintas dan adanya rujukan ke rumah sakit. Pengajuan reward diajukan oleh PIC (Person in Charge) masing-masing unit kepada Divisi Keselamatan dan Lingkungan jika point mereka sudah mencapai 100. Selanjutnya Divisi Keselamatan dan Lingkungan memberikan tembusan kepada koperasi PT. KTI, agar pekerja pada unit tersebut mendapatkan hadiah berupa sembako.

Pelaksanaan program reward zero ccident sebenarnya sudah hampir sempurna, hanya terdapat 1 kriteria yang tidak terpenuhi. Kriteria tersebut adalah nilai kembali menjadi 0 jika terjadi kecelakaan kerja berupa kebakaran, kecelakaan lalu lintas dan rujukan rumah sakit. Hal ini disebabkan masih adanya pekerja yang menyembunyikan kecelakaan yang dialaminya agar penilaian unit mereka tidak kembali menjadi 0. Berdasarkan hasil wawancara, diketahui bahwa kejadian tersebut tidak hanya dilakukan oleh pekerja yang bersangkutan, namun juga didukung oleh rekan bahkan hingga person in charge (PIC) di unit tersebut.

\section{Pengecekan APAR, Hydrant dan listrik}

Program pengecekan Alat Pemadam Api Ringan (APAR), hydrant dan listrik dilakukan rutin setiap bulan. Pengecekan dilakukan oleh representatif Divisi KL. Bagi APAR yang telah kedaluwarsa, maka akan diganti.

Berdasarkan hasil observasi lapangan, diketahui program pengecekan APAR, hydrant dan listrik memenuhi 3 dari 4 kriteria. Hal ini disebabkan pengecekan listrik tidak dilakukan secara rutin sebulan sekali. Seharusnya pengecekan listrik dilaksanakan bersamaan dengan pengecekan APAR dan hydrant. Saat di lapangan, petugas hanya melakukan pengecekan terhadap APAR dan hydrant. Keterbatasan waktu menjadi alasan utama pengawas tidak melakukan pengecekan instalasi listrik. 


\section{Safety Riding}

Safety Riding adalah program inspeksi pekerja yang memakai sepeda motor. Kegiatan ini dilakukan 2 bulan sekali pada pukul $06.00-$ selesai. Inspeksi yang dilakukan meliputi kelengkapan STNK, SIM, penggunaan helm dan peralatan sepeda motor. Program ini dilakukan oleh Divisi KL bekerja sama dengan security PT. KTI. Pelanggaran yang ditemukan akan dilaporkan kepada personalia untuk selanjutnya diberikan SP (Surat Peringatan). Tujuan program ini adalah untuk membentuk sifat disiplin dan mematuhi peraturan dalam berkendara agar terhindar dari kecelakaan.

Program safety riding memenuhi 3 dari 5 kriteria. Berdasarkan hasil observasi lapangan diketahui bahwa pelaksanaan safety riding dimulai pukul 06.00 WIB yang seharusnya pukul 05.00 WIB. Pelaksanaan yang terlambat menyebabkan banyak pekerja yang tidak terkena sidak. Selain itu, tindak lanjut pekerja yang diketahui melanggar tidak jelas. Berdasarkan hasil wawancara dengan representatif Divisi KL, pekerja yang melanggar akan dilaporkan kepada personalia. Tidak jelas hukuman apa yang diberikan oleh personalia.

\section{Bis Karyawan}

Bis Karyawan mulai dilakukan pada tahun 2012. Dalam pelaksanaannya tidak semua karyawan PT. KTI menggunakan bis karyawan. Hal ini disebabkan keterbatasan bis karyawan yang belum mampu untuk memberikan fasilitas antar jemput kepada semua pekerja. Oleh karena itu dibuat daftar pekerja yang wajib menaiki bus karyawan. Daftar tersebut disesuaikan dengan lokasi rumah pekerja. Jika rumah pekerja tersebut dekat dengan jalur yang dilalui oleh bis karyawan, maka pekerja tersebut wajib menaiki bis karyawan. Pelaksanaan program ini bertujuan untuk mengurangi kecelakaan lalu lintas pada pekerja PT. KTI saat berangkat maupun pergi bekerja.

Berdasarkan hasil wawancara dengan beberapa pekerja, diketahui program bis karyawan hanya memenuhi 1 dari 3 kriteria. Hal ini disebabkan masih adanya pekerja yang tidak menggunakan fasilitas bis karyawan, meskipun namanya telah tercantum. Alasan pekerja tidak menaiki bis karyawan bermacam-macam, beberapa di antaranya adalah telat bangun, malas menunggu dan merasa kurang nyaman. Pekerja yang tidak menaiki bis karyawan seharusnya mendapatkan sanksi, namun kurangnya pengawasan menyebabkan banyak pekerja yang lolos.

\section{Penyusunan dan Pelaksanaan JSA}

Penyusunan dan pelaksanaan JSA masih memenuhi 3 dari 7 kriteria. Penyusunan JSA sudah sesuai dengan SOP, namun pelaksanaannya tidak sempurna. JSA hanya ditempel di kantor-kantor saja, seharusnya JSA juga ditempel di lapangan atau tempat produksi, karena pekerja produksi saat bekerja banyak kontak dengan mesin-mesin yang memiliki risiko tinggi, seperti panas, benda tajam, dan tertimpa bahan. Oleh karena itu, pekerja lapangan lebih rentan terhadap terjadinya bahaya. Pekerja juga tidak diberikan safety talk atau safety briefing sebelum bekerja. Hal-hal tersebut diatas menyebabkan pekerja tidak memahami bahaya di tempat kerja mereka, sehingga cenderung melakukan unsafe action .

\section{Promosi K3}

Pelaksanaan promosi K3 di PT. Kutai Timber Indonesia memenuhi 3 dari 6 kriteria. Berdasarkan hasil observasi lapangan ditemukan banyak ramburambu lalu lintas yang sudah kusam, sehingga tulisan dan gambar yang tertera kurang jelas. Selain itu penempatan beberapa media promosi K3 kurang strategis, karena susah ditemukan dan dilihat.

\section{Pelaksanaan K3}

Hasil observasi lapangan menunjukkan masih banyak pekerja yang belum tertib dalam menjalankan peraturan yang berkaitan dengan kesehatan dan keselamatan kerja. Pelanggaran yang sering kali terjadi adalah pekerja tidak menggunakan alat pelindung diri sesuai dengan bahaya pekerjaannya. pelanggaran lain adalah pekerja masih ada yang mengendarai forklift lebih dari $35 \mathrm{~km} / \mathrm{jam}$.

\section{SIMPULAN}

Kinerja K3 di PT. Kutai Timber Indonesia cenderung tidak mengalami perubahan yang berarti. Peningkatan kinerja K3 PT. Kutai Timber Indonesia hanya terjadi pada tahun 2015. Hasil ini menunjukkan bahwa program pengendalian kecelakaan kerja di PT. Kutai timber Indonesia tidak mengalami banyak perubahan. Hal ini terbukti dengan tidak adanya perubahan program kerja selama tahun 2012-2016. 


\section{DAFTAR PUSTAKA}

International Labour Office., 1989. Pencegahan Kecelakaan. Jakarta: PT. Pustaka Binaman Pressindo.

Joint Australian/New Zealand Standard., 2001. Risk Management AS/NZS 4801:2001. Sydney: Standards Australia International

Kumar, A., 2015. Analysis of Safety Performance Rating in Thermal Power Plant. International Journal of Emerging Technology and Advanced Engineering. 5(1): pp. 120-128.

Romadiaty, F., 2011. Evaluasi Penerapan Prosedur Operasional Sistem Manajemen Keselamatan dan
Kesehatan Kerja (SMK3) di PT. Petrokima Gresik. Jurnal Teknik dan Manajemen Industri. 6(2): pp. 97-105.

Peraturan Menteri Tenaga Kerja Republik Indonesia No. 3 Tahun 1998 Tentang Tata Cara Pelaporan dan Pemeriksaan Kecelakaan. Jakarta: Kementerian Tenaga Kerja.

Silalahi, B., Rumondang., 1995. Manajemen Keselamatan dan Kesehatan Kerja. Jakarta: PT. Pustaka Binaman Pressindo.

Tyler, M., 2007. Tolley's Workplace Accident Handbook. Second Edition. Burlington: Elseiver. 